\title{
Enhancing the Regional Medium Students' Vocabulary Using Self-Directive Learning Techniques
}

\author{
Dr. Rambabu Battu ${ }^{1}$, Vemaiah.Beesupogu \\ Associate Professor, Department of Humanities and Science, St.Mary's Group of Institutions Hyderabad, India. \\ Asst.Professor, Department of Humanities and Science, St.Mary's Engineering College, India
}

\begin{abstract}
Learning vocabulary is one of the major problems for foreign and second language learners. It has been neglected or considered as a secondary emphasis in English as a Second Language and English as a Foreign Language programs. Since many researchers Twaddle (1973) Wilkins (1974) and Judd (1978) claim that little importance has been given to vocabulary in the language class. Learning a language mainly involves learning its grammar, vocabulary, and how to use them in appropriate way. Vocabulary is an important component in leaning a language. Hill, (2005: 1) said that "Vocabulary has long been considered an important element in language learning. It may be considered as "the building block to communication." Wilkins (1974:111) states, "Without grammar very little can be conveyed, without vocabulary nothing can be conveyed". All the statements mentioned above suggest that, words are identified as one of the essential components of a language, and essential for any form of communication to materialize either it is written or spoken.
\end{abstract}

Keywords: Vocabulary, Language and Grammar.

\section{INTRODUCTION}

\section{Necessary to Teach Vocabulary}

There are two different schools of thoughts about whether vocabulary should be taught at all: one supports the idea that vocabulary should be taught to the learners and the other does not. However, researchers emphatically support the necessity of teaching and learning vocabulary in L2 for the following reasons:

- Students know only a limited number of words (Laufer, 2000).

- Students have limited knowledge of secondary meaning senses (Schmitt, 1998).

- Students use L1 translations when understanding the meaning of L2 words (Jiang, 2004).

- Students have limited awareness of the different derivative forms of a word (Schmitt and Zimmerman 2000: 145-171).

Therefore teaching and learning vocabulary should not be abandoned, more so, in the case of the regional medium (Telugu Medium) students. The necessity of vocabulary acquisition for them cannot be underscored. For them classroom is the immediate available source to learn vocabulary. So, practicing self-directive strategies are much more important for the regional medium students. The word learning strategies made the students more independent and help them to learn words effectively.

\subsection{Learning Strategies}

In order to develop the regional medium students' vocabulary, the language teachers need to facilitate self-directive or students centered strategies in the language classroom. In this regard, Waring (2002:25) claims that teaching a word don't mean students have learned it, and the fact that students have finished a unit should not mean they have mastered all the words in it. As a result, besides the effort of maximizing the efficiency of teaching, there should be an equal or even more investigation of the nature of the learning process the students under go. Because students are the most responsible bodies to enrich their word power, it is essential to high light the importance of learning strategies. As they are;

${ }^{1}$ Corresponding Author:battu.ram@gmail.com 


\section{VOCABULARY NETWORK}

The principle of vocabulary network, also known as word web, word map, mind map, word association, explains that beyond sameness, oppositeness and inclusion of meanings of words, there is an intricate and complex interconnection or network among group of words. McCarthy (1990) writes that semantic relationship in terms of synonymy and antonyms tends to simplify the complex nature of the mental lexicon. According to Schmitt (2000), words are not stored in the mind in isolated pattern, but in an organized and systematic manner. That organization is conveniently explained as association or network. In making use of vocabulary network technique, Harmer (1990:165) suggests that a word item, for example, 'HOUSE" is selected and given in a box at the centre of a sheet of paper and students are encouraged to build a network of arrows connecting it to many possible words that have semantic association in any way. See a more complicated network for the word 'BEDROOM' in Gairns and Redman (1986: 97). Below is given a simple example of word network (Ur 1996: 69).

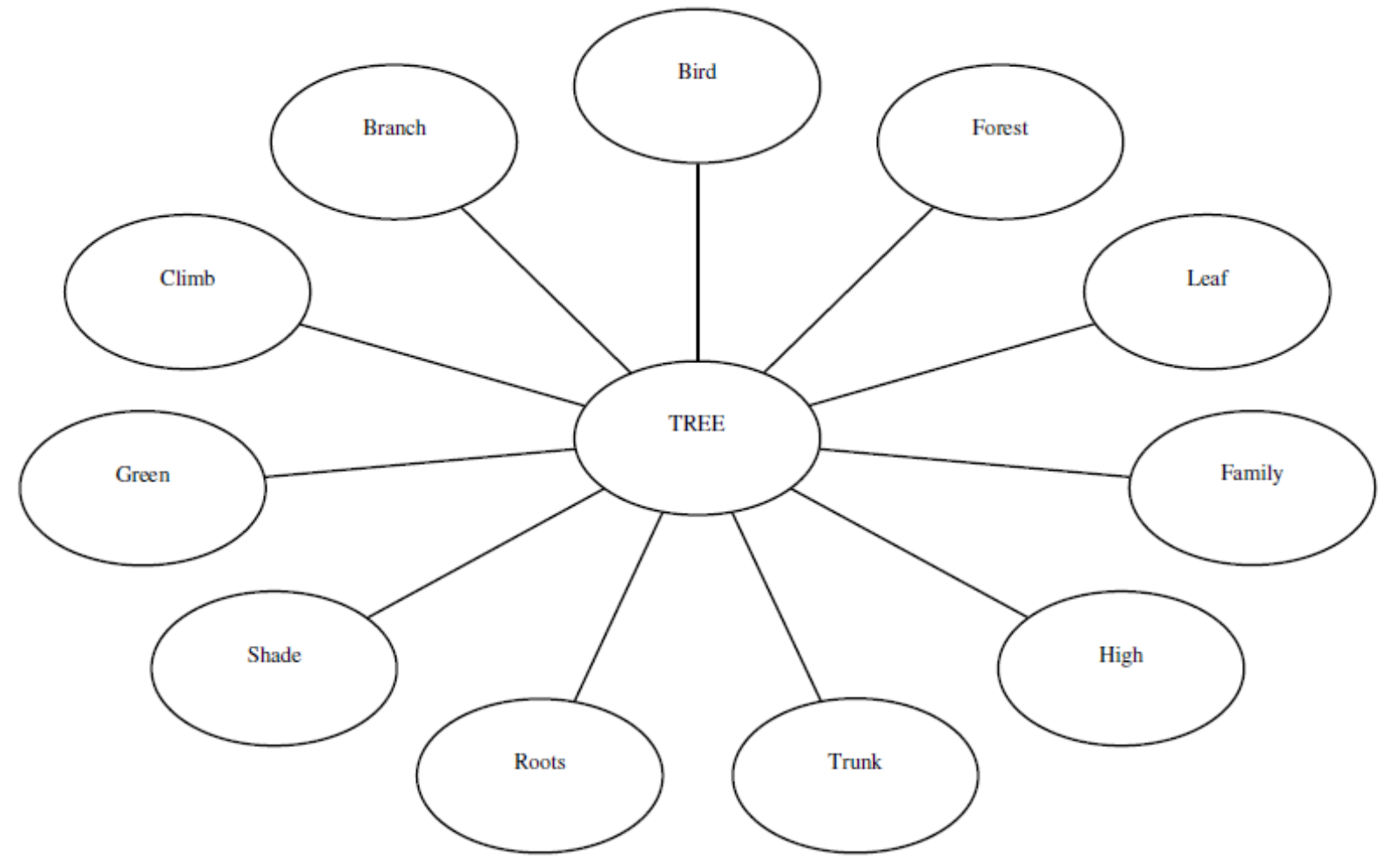

\section{Diagram showing word association / Vocabulary network}

Fig1. Word Network

The vocabulary network technique is believed to function as a convincing framework of organizing lexical items.

\subsection{Guessing from Context}

Guessing word meaning of a word is another important strategy in order to develop the regional medium students' vocabulary. Beglar and Hunt (2005) write that the ability of guessing meaning from context is an essential strategy enhancing vocabulary acquisition and commonly used by successful language learner. Some writers, for instance Nation (2001), underlined although guessing is a key vocabulary learning strategy, practically it can be a complicated process for a number of reasons : absence of sufficient clues, limited exposure of the word across the text, level of text difficulty, familiarity of the topic, learners' background knowledge and interest to mention some. Due to these limitations, scholars such as Coady and Huckin (1997), Nation (2001), Schmitt (2000), Carter and McCarthy (1988) suggest additional explicit independent word learning strategy, the use of dictionary. Research also shows that learners who employed dictionary together with guessing from context not only learned more words 
immediately but also recalled better after several weeks compared to those who used inference strategy alone (Laufer and Hadar 1997, Laufer and Hill 2000).

\section{DICTIONARY USE AND VOCABULARY LEARNING}

The use of dictionary is the second major self-directive learning strategy learners go for discovering the meaning of new words. Research indicates definition and examples about the actual use of a word in a dictionary enable learners to successfully use new words in their own sentence meaningfully. A part from meaning, a good dictionary obviously provides a lot of information about a word including spelling, pronunciation, synonymy, antonymy, collocation, etc. Scholars also recommend, Laufer and Hadar (1997) in Gu (2003), Beglar and Hunt (2005), Gairns and Redman (1986), that monolingual dictionaries are more useful than bilingual dictionaries. Therefore, students have to be trained how to use a monolingual dictionary effectively.

To keep the students' flow of concentration, avoid consumes time and use dictionaries effectively. The language teacher has to teach a few tips to the students. They are:

- Using an alphabet list;

- Removing affixes, if necessary, to identify the base form of the word;

- Using the context to decide which is needed; and

- Using the context to decide which meaning is appropriate.

\subsection{Word Cards}

Apart from the strategies mentioned above, word card strategy is a great effect on learning vocabulary. Some of the advantages of using word cards are:

$>$ They are far more portable than dictionaries, textbooks, or notebooks

$>$ They are more durable than sheets of paper

$>$ They are attractive in different colours

$>$ They are made by learners and the frequent review of the cards lead to word memory.

A proper introduction to the method of card making is important in order to make the students to clearly understand the various steps. Before going to make word cards the teacher have to gave clear instructions and introduce models of different colourful cards with size of $5 \times 4$. The suggestions are followed to prepare word cards are:

\section{Steps}

Drite a word, its pronunciation and its part of speech on one side of the card.

$>$ On the second side of the card, write meaning in their mother-tongue as well as in English

$>$ On the same (second) side, write the usage of the word. Zimmerman (2009: 125)

Note to the students: Do not write too much like collocation, different sample sentences, and idioms or phrasal verbs.

Sample word card:

Side 1

\section{trust /trast/ noun, verb}

Side 2

$$
\text { సమ్మకము, విశ్వాసము }
$$

noun believe that somebody or something is good, sincere, and honest. A partnership is based

$$
\text { on trust. }
$$

verb I trust in God. 


\section{CONCLUSION}

Finally, concluding that the vocabulary learning strategies mentioned above are most useful and suitable for the regional medium students. By using this type of strategies in proper way would enhance the students' vocabulary knowledge and help the students in their further studies. It is also depends on the best practice of the students in the classroom and outside. Here, the language teacher acts as a facilitator and guide, giving instructions and clearing doubts of the students. Without proper instructions, guidance and encouragement in the class it could not be succeed. Apparently the language teacher has greater role, in the process of developing the students' vocabulary.

\section{REFERENCES}

[1] Beglar, D. and Hunt, A. (2005). A Framework for Developing EFL Reading Vocabulary: unpublished article, available at http://ntlrc.Hawaii.Edu/rfl/april2005/hunt/hunt/html

[2] Brown, D.H. (1994). Principles of Language Learning and Teaching. London: Prentice Hall reagents.

[3] Carter, R. and McCarthy, M. (1988). Vocabulary and Language Teaching. United Kingdom: Longman Group.

[4] Coady, J. and Huckin T. (1997). Second Language Vocabulary Acquisition. Cambridge: Cambridge university press.

[5] Judd, E. L. 1978. Vocabulary teaching and TESOL: a need for re-evaluation of existing assumptions. TESOL Quarterly 12, 1: 71-76.

[6] Laufer,B.,\&Hadar, L. (1997). Assessing the effectiveness of monolingual, bilingual, and "lingualized" dictionaries in the comprehension and production of new words. Modern Language Journal, 16 (1), 189-196.

[7] Lewis, M. (1993). The Lexical Approach. Language Teaching Publications.

[8] Ellis, R. (1994) The Study of Second Language Acquisition. Oxford: Oxford University Press.

[9] McCarthy, M (1990) Vocabulary. Oxford: oxford University Press.

[10] Schmitt, N. (2000) Vocabulary in Language Teaching. Cambridge: Cambridge University press.

[11] Twaddell,F. (1973) Vocabualry Expansion in the TESOL Classroom. TESOL Quarterly, 7 (1) pp 61-79).

[12] Walker, B.J. (1988). Diagnostic Teaching of Reading: Techniques for Insrtuctions and Assesment. N.Y. Merill Publishing Company.

[13] Ur, P. (1996). A Course in Language Teaching: Practice and Theory. Cambridge: Cambridge University Press.

[14] Nation, I.S.P. (2001). Learning Vocabulary in Another Language. Cambridge University Press, Cambridge.

[15] Waring, R. (1999). Tasks for assessing second language receptive and productive vocabulary. PhD Thesis [Online]. Available: http://www1.harenet.ne.jp/_waring/papers/phd/title.html [2000, Nov 27].

[16] Wilkins,D.A. (1974). Reading in The Language Classroom. London: Macmillan Publishers Ltd. 